\title{
Research in third world countries: Pugwash plans controls
}

Pugwash, the international organisation of concerned scientists usually associated with nuclear disarmament, set up a workshop in Delhi in January to resolve an urgent new problem: the relationship between researchers in the first and third worlds. Feeling has been building up in developing countries over the past eighteen months against collaborations between the rich 'northern hemisphere' and the poor south-where the north provides most of the money and consequently determines the research priorities. Such research is always to the long term bencfit of the north and to the disbenefit of the south, in the third world view.

Dr Geoffrey Oldham, deputy director of the Science Policy Research Unit (SPRU) at the University of Sussex. told a Sussex seminar last week that the feeling generated by the perceived or misperceived wrongdoings of the north is so strong that India, for example, had practically closed up shop on such collaborations.

So Pugwash, shifting towards an interest in science in developing countries, has stepped in to try to set up 'guidelines' for such research that would allay third world fears.

The fears centre on eight main issues, Dr Oldham said. The first is scientific colonialism: that first world researchers exploit cheap research labour, or lax safety and health regulations, to do their own research abroad under the pretext of collaboration. The third world scientists involved are left untrained. and when the visiting team withdraws it takes its data with it.

The second concern is that since most of the collaborations are funded from the north. and since the north determines the nature of the research, the north is making a 'de facto' determination of the science policy of the south.

The third fear is a more common one: that the north is exploiting the south commercially through its research. An example, said Dr Oldham, was research in Lagos on the conversion of the cassava root to gari, a flourlike West African staple. The traditional process takes the village housewife five days of hard labour, and Lagos had been working on the physics and biochemistry of the conversion in an attempt to speed it up. Lagos solved the scientific problems, but baulked at the engineering necessary to turn their discoveries into a practical process. So a Bristol firm moved in "under the guise of scientific collaboration", dealt with the engineering difficulties, and promptly claimed world patent rights. Most of the fruits of the work have therefore accrued to the firm, claimed Dr Oldham.

The fourth problem is that most collaborations have failed to stimulate the growth of scientific and technical capabilities in the third world host country: there has been no transfer of expertise.

The fifth has been raised by the "several cases" where pharmaceutical companies have instituted drug trials on developing country nationals under conditions that would have been forbidden in the north.

The sixth fear is that one of the objectives of collaboration is to discover bright researchers in the developing countries and to cull them for research in the north-or whether that is an objective or not, that the resuit of such collaboration is often the loss of the best talent from the country.

Next is the observation that of the total research effort in the north only a tiny fraction is availabie for collaboration with the south; more than $50 \%$ of the north's research is under military wrappers, and a further substantial fraction controlled by the constraints of industrial secrecy. So seen as an effort at the transfer of expertise, it is at best very partial.

The eighth and last concern is the one that brought affairs to a head: the fear, generated by the 'discovery' of two such cases in India, that collaborative agreements made ostensibly for non-military reasons are in fact being conducted to further the military ad-

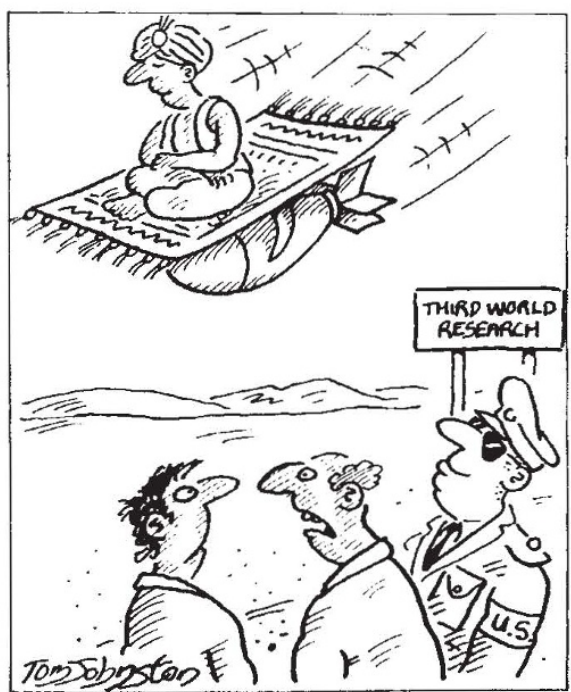

"It started out as joint research into textiles!" vantage of the north. The first of these cases was the celebrated issue of the impotent mosquito, a programme launched by WHO to introduce floods of impotent males into the mosquito population and so control the development of the mosquito-borne parasites of filaria, denge fever, and malaria. The programme concentrated on the species responsible for filaria and denge, and neglected the more prevalent malaria (which at the time was coming under the control of DDT). The Indian press claimed that the real objective of the research was the investigation of biological warfare using denge fever.

At a time when malaria was on the increase again the press charged that: the priorities of the research were not consistent with Indian needs; that the chemical sterilisers used were very toxic in the environment, and potentially dangerous; that their use would have been disallowed in the US; that possible mutations could lead to more dangerous strains; and that the concern of the research with the use of denge in biological warfare was "quite blatant".

WHO responded with its own explanation, but whatever the rights and wrongs of the case the seed of distrust had been sown. And it was germinated by the discovery that the Bombay Natural History Society's collaborative project on the study of migratory birds as a carrier of disease was funded by the Migratory Animals Pathological Survey-a branch of the US Army. Migratory birds and other animals, which follow very predictable paths, would be very effective carriers of biological warfare agents.

There thus arose a tremendous backlash in India against collaboration, leading to what Dr Oldham called "almost a complete closure of doors". This nervousness spread around, said Dr Oldham, and has led to most developing countries setting up some government agency to assess collaborative research projects.

In this atmosphere, and with a view to making a presentation at the 1979 United Nations Conference on Science and Technology for Development, a Pugwash workshop met in Delhi in mid-January to see if they could agree to a set of 'guidelines' to inform and control future collaboration. They could not-though they produced a draft set and instructed the Indian group to complete it, for initial submission to a four-man 'editorial board' and its ultimate adoption by the Pugwash council.

Agreement was reached that the guidelines should not extend to commercial agreements, a vexed area which Pugwash was happy to leave to the forthcoming UN Conference on 
Technological Cooperation among Developing Countries (TCDC). On the science, said Dr Oldham, the meeting took "a very positive approach". Whereas it could have become a forum for recriminations, looking only for controls on the negative effects of collaboration, the workshop took pains to find ways of enhancing the benefits.

The workshop recognised that it was developing guidelines in an area which was relatively little researched. "We had to go by anecdotes," said Dr Oldham. SPRU's own 'Project Perseus', which had looked at the effects of international collaboration among OECD countries (principally Europe, America, and Japan), had run into a problem in defining 'success', and had been unable to come to many policy recommendations - except to point out that the more basic the research, the more successful the collaboration.
Beyond that, some work in Thailand had shown that the most highly regarded research had involved longperiod collaborations.

The rest lay with hearsay and experience, said Dr Oldham, though he was inclined to accept the views of one of the most experienced members of the workshop--Dr Nayudamma, sometime head of both the central leather research institute, Madras, and India's CSIR. Nayudamma criticised the international organisations such as FAO, UNIDO, ILO, UNESCO, WHO, UNEP, and ESCAP, who he said had all tried at one time or another to claim leather as their territory, all, said Nayudamma, "fishing for projects". Success came, according to Nayudamma: when there was clear understanding of the purposes of the collaboration on both sides; when the main objective was the active building up of local expertise; when there was trust and friendship at the top; when statuses were equal; when consultation was continuous; and when the research was more basic than applied.

"As a researcher," said Dr Oldham, "I've felt the need for information. The anecdotes might be aberrations. It looks like an interesting topic for further research. But the developing countries have a very considerable concern about the experience of collaboration. All of us must take this very seriously",

Robert Walgate

Nature would welcome hearing from scientists, particularly in the third world, whose experience of scientific collaboration between the first and third worlds might shed light on this issue
A RECENT visit to eastern Asia allowed me to see something of the pollution problems in several countries. During the last twenty or so years, since the world-wide public interest in the environment has developed, Japan has been castigated as the prime example of the danger of pollution from rapid industrial growth. Every text in this field describes horrific air pollution in Tokyo and other cities, as well as the tragic mercury poisoning at Minnemata.

My first impression of Tokyo was one of surprise; the air seemed as clean as that of London. This impression was confirmed when I visited the Environmental Agency, and met Dr Michio Hashimota, Director of the Air Quality Bureau. I saw the records which showed that up to some ten years ago the air in the Japanese cities deserved its reputation, but that since then the improvement had been spectacularly rapid. Levels of smoke and soot are now as low as in most western cities, and those of sulphur dioxide are lower.

This improvement is the result of vigorous government action, with scientists like Dr Hashimoto in the van. Up of to the mid nineteen sixties, he said "Japan had been heaven for polluters". Now this had changed, and "For the last ten years, it has been hell". The earlier period had been that of the 'Japanese miracle' of unprecedented economic growth, when the environment had come a bad second. However, those who said that growth and pollution must always go hand in hand have now been shown to be wrong. It is true that the rate of growth has slowed down somewhat, but the process has not been reversed. The clean air of today exists with substantially greater industrial production than existed with the foul air of ten

years ago.

Although Japan has not solved all its problems, the impressive new Institute for Environmental Studies, with facilities most scientists in other countries would envy, demonstrates their intention to prevent anything like a

\section{Heaven and Hell}

\section{Sorry, for copyright reasons some images on this page may not be available online}

\section{KENNETH MELLANBY}

second Minnemata. Regulations are strictly enforced, and controls are costing industry a great deal of money. However, it is realised that this may sometimes be a good investment. Quite apart from the loss of life and the misery caused to the afflicted, it now appears that the sum that has been paid in compensation to the Minnemata victims is astronomically greater than it would have cost to contain the waste mercury discharged by the industry.

Conditions today are somewhat dif- ferent in South Korea and Taiwan. In both these countries industrial growth of the kind previously seen in Japan is taking place, but the programme of both growth and of environmental amelioration is ten years behind. Pollution control is not yet a priority, though the authorities are now becoming aware of the problem, and I expect they will soon follow Japan's good example. But they have not yet started to do so. In Taiwan, on the edge of the booming city of Taipei, just beyond the new and magnificent Grand Hotel, rises the mountain of Yang-min Sang. This was once noted for the purity of its air, one reason why before dawn hundreds of Chinese trek upwards to sites where they perform Tai Ch'i Chuan, Taikwondo, Karate and other exercises and martial arts practised to develop mental and physical fitness. Unfortunately the devotees are not getting the benefit of pure air, for this today is much more polluted than that of central Londonor of Tokyo.

Some European environmentalists are reluctant to believe that the conditions in Tokyo are so improved. They produce photographs of the citizens in the streets wearing masks over their faces, which they say is done because of the dirt in the air. This suggestion amuses the Japanese, who actually are only being socially responsible. They wear masks when they have a cold and do not wish to infect their colleagues. They have taken the transmission of infection more seriously than we have in Britain, where the war time slogan "Coughs and sneezes spread diseases' seems to have been forgotten, judging from the behaviour of many passengers in public transport who make little attempt to keep their germs to themselves. 